\title{
Dynamic Characteristic of the Medium Span Concrete Footbridges
}

\author{
Marek Pańtak \\ Department of Bridges and Tunnels Construction, Cracow University of Technology, Cracow 31-155, Poland
}

\begin{abstract}
Concrete footbridges, due to their mass, stiffness and damping, are perceived as structures more resistant to vibration caused by dynamic action of the users. In order to verify the dynamic behaviour of concrete footbridges, a series of field tests and numerical analyses have been carried out. In the paper, the results of the dynamic field tests of three medium span concrete footbridges with different structural systems (frame, beam and arch footbridges) and their dynamic characteristics (mass, stiffness and damping) are presented. The field tests were carried out for different types of vibration excitation caused by walking, running and jumping persons. Furthermore, the vibrational comfort criteria for footbridges are shortly described and verified for examined structures. The study were supplemented by numerical calculation of natural mode shapes and frequencies of the structures using the 3D FEA (finite element analysis) models with elastic supports elements in order to ensure the compatibility of the calculated and measured mode shapes of the footbridges.
\end{abstract}

Key words: Footbridge vibrations, concrete footbridges, comfort criteria.

\section{Introduction}

Properly designed civil engineering structures should fulfil the requirements of two principal limit states: the ultimate and the serviceability limit state. The conditions of the serviceability limit state require among other things to limit the structure vibrations.

In the case of footbridges, acceptable levels of vibration acceleration, resulting from the requirements of the vibrational comfort criteria for walking people, are in the range of $a_{v, \max }=0.5-1.0 \mathrm{~m} / \mathrm{s}^{2}$ for vertical vibrations and $a_{h, \text { max }}=0.1-0.2 \mathrm{~m} / \mathrm{s}^{2}$ for horizontal vibrations [1-7]. For rare and special dynamic loads (impact of large crowd or intentional excitation (act of vandalism)), acceptable levels of vibration acceleration are in the range of $a_{v r \text {, max }}=0.85-1.2 \mathrm{~m} / \mathrm{s}^{2}$ for vertical vibrations and $a_{h r \text { max }}=0.2-0.3 \mathrm{~m} / \mathrm{s}^{2}$ for horizontal vibrations [1-7]. If these vibration comfort requirements are exceeded more than once a week, it is advisable to take a countermeasures to change the

Corresponding author: Marek Pańtak, Dr., research fields: bridge design, construction and bridge dynamics. E-mail: mpantak@pk.edu.pl. dynamic characteristics of the structure by modifying the structural system or by installing vibration dampers.

Generally, the concrete structures are characterised by high mass, high stiffness and in some cases also by high damping. These main features of the concrete structures can lead to their low dynamic susceptibility and low vibrations amplitudes. The concrete footbridges are perceived as structures more resistant to vibration caused by dynamic action of users than steel or composite footbridges. In further part of the article, the dynamic characteristic of three concrete footbridges obtained during numerical dynamic analyses and the field tests of a beam, rigid frame and arch footbridges (Fig. 1) with medium span length (35.0-70.0 m) are presented.

\section{Dynamic Characteristic of Tested Concrete Footbridges}

\subsection{Footbridge over A4 Motorway between Stanisławice/Kłaj Rest Area, Poland}

The footbridge was built in July, 2011. This is a 
three-span frame footbridge with spans $14.0 \mathrm{~m}+$ $34.0 \mathrm{~m}+14.0 \mathrm{~m}$ and with total length of the main structures $64.0 \mathrm{~m}$. Access to the footbridge is ensured by stairs and ramps for disabled persons (Fig. 1a). The structural system is a rigid frame with inclined piers rigidly connected with girders and with foundation plates. Both foundation plates $(6.0 \mathrm{~m} \times 5.0 \mathrm{~m} \times 1.2 \mathrm{~m})$ are founded on 18 inclined concrete piles $\varnothing 500 \mathrm{~mm}$. Main girder is vertically curved (the radius of curvature $R=330.0 \mathrm{~m}$ ) and is made with prestressed concrete $\mathrm{C} 45 / 55$. The inclined footbridge piers $(0.5 \mathrm{~m}$ thick) are made with reinforced concrete $C 35 / 45$. The width of the piers varies from $1.5 \mathrm{~m}$ at the connection with the foundation plate to $1.0 \mathrm{~m}$ at the connection with the main girder. The footbridge deck is connected with ramps for disabled persons by means of composite steel-rubber expansion joints cover. The width of the dilatation gap on the both ends of the footbridge is $30 \mathrm{~mm}$. In Fig. 2, the longitudinal section and cross section of the footbridge are presented.

The dynamic field tests of the footbridge were carried out in September, 2013. In numerical dynamic analysis of natural frequency and mode shapes of the footbridge, the time dependent material constants, after two years of footbridge operation $(t=730 \mathrm{~d})$, were used according to Ref. [8]: for footbridge deck $\mathrm{C} 45 / 55: E_{c m}(t)=40.0 \mathrm{GPa}, \gamma_{m}=2,600 \mathrm{~kg} / \mathrm{m}^{3}$ - density of concrete; for footbridge piers C35/45: $E_{c m}(t)=37.0$ $\mathrm{GPa}, \gamma_{m}=2,500 \mathrm{~kg} / \mathrm{m}^{3}$. By accepting a higher density of concrete for the footbridge deck in computational FEA (finite element analysis) model, the additional weight of railings, plexiglass screens and steel pillars on the footbridge deck $(170 \mathrm{~kg} / \mathrm{m})$ have been taken into account in calculations of natural frequencies and mode shapes of the footbridge.
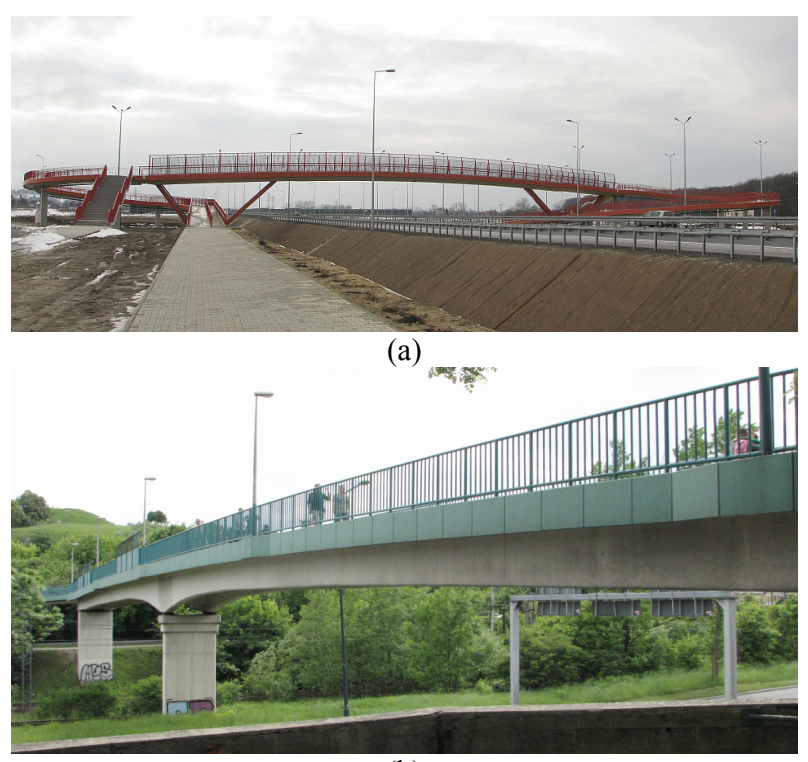

(b)

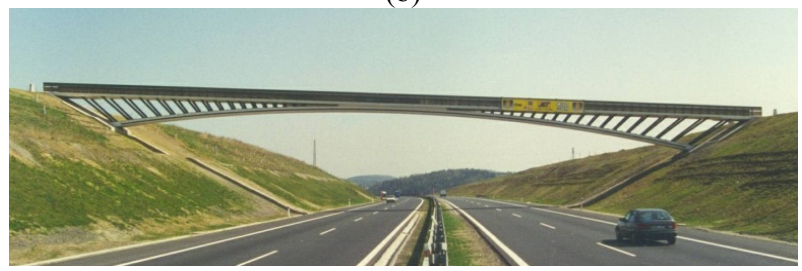

(c)

Fig. 1 Tested footbridges: (a) footbridge over A4 motorway within Stanisławice/Klaj Rest Area, Poland; (b) footbridge over Powstanców Śląskich Av. in Kraków, Poland; (c) footbridge over D5 motorway near Cekov, Czech Republic [9].

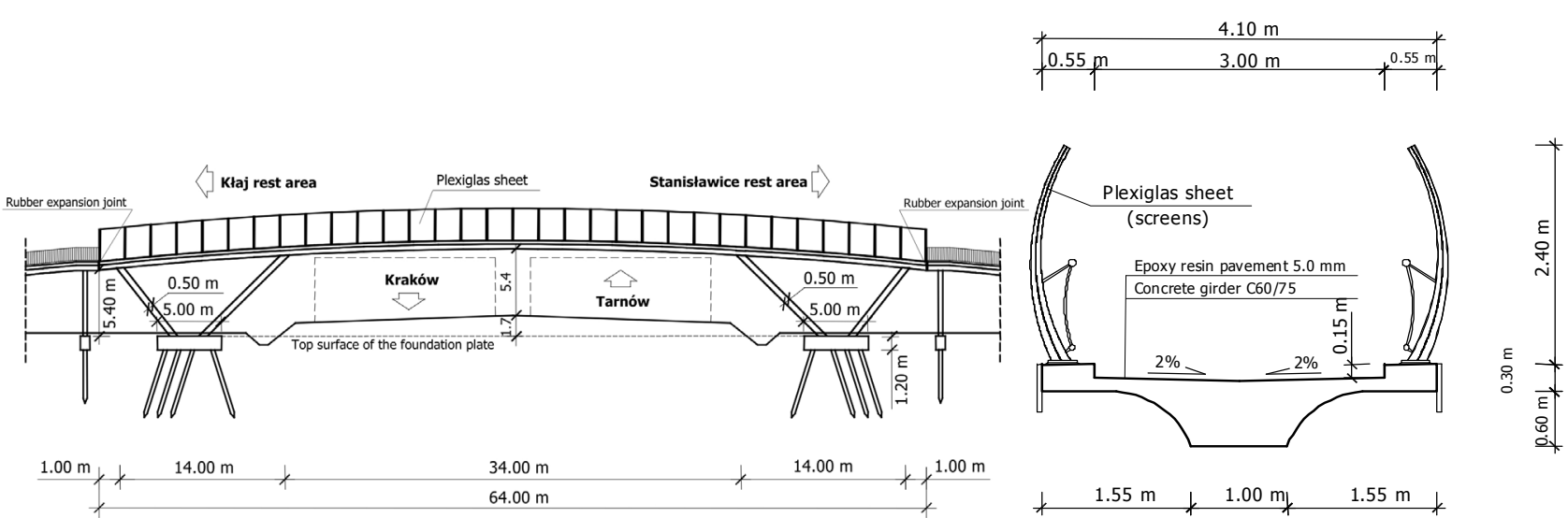

Fig. 2 Footbridge over A4 motorway between Stanislawice and Klaj Rest Area. 
The computational FEA model of the footbridge was prepared in AASP (Autodesk Algor Simulation Professional). The 3D model was built using 3D brick elements available in the AASP software. Because the bridge is a rigid frame structure for further analysis, it was important to properly model the connection between the piers and the foundation plates. Due to the lack of detailed data of soil parameters, the stiffnesses of spring (elastic) connection in $X, Y$ and $Z$ direction $\left(k_{x}, k_{y}, k_{z}\right)$ for translational and rotational degrees of freedom of the footbridge foundations were assumed to ensure the compatibility of the first calculated and measured mode shapes of the footbridge. The nodal boudary conditions for footbridge piers were modeled as spring supports with stiffness of the spring for translational DOF (degree of freedom) $k_{T x}=10.80 \mathrm{GN} / \mathrm{m}, k_{T y}=k_{T z}=3.60 \mathrm{GN} / \mathrm{m}$ for each footbridge pier. The stiffnesses of the spring elements for rotational DOF $k_{R x}=k_{R y}=k_{R z}$ had no impact on the footbridge natural frequency and were modeled as fully constrained ( $X$-longitudinal axis of the footbridge, $Y$-transverse axis, $Z$-vertical axis). Connection between footbridge deck and the ramps for disabled persons due to incorrect implementation of composite steel-rubber expansion joints cover (in a very small dilatation gap) was modeled with constrained $X$ translation. For $Y$ and $Z$ translations, $k_{T y}=k_{T z}=1.70 \mathrm{MN} / \mathrm{m}$ was assumed. The rotational DOF for $Y$ and $Z$ rotations were modeled as unblocked (free) due to a possibility of deformation of the rubber expansion joint cover in these directions.

During the numerical modal analysis, several mode shapes with frequency in the frequency range of human dynamic impact during walking, running or jumping were calculated (Fig. 3). During the field tests, the first two mode shapes were identified with frequency $f_{t 1}=1.14 \mathrm{~Hz}$ and $f_{t 2}=2.35 \mathrm{~Hz}$. The dynamic tests were performed by walking, running and jumping persons. The vibration acceleration was measured by three two-axis accelerometers mounted on the edge of the footbridge deck in $1 / 2 L, 1 / 3 \mathrm{~L}$ and $2 / 3 L$ ( $L$-length of the footbridge span). To identify the mode shapes of the footbridge, the correlation of the measuring signal from each accelerometers in two directions (vertical and horizontal transverse to footbridge axis) was verified. The footbridge vibrations were induced by one to three walking, running or jumping persons using the metronome set at a rate corresponding to the natural vibration frequencies of the footbridge.

The first mode shape of the footbridge was very often excited by vans, lorries and buses passing under the footbridge. The amplitude of the horizontal acceleration was very small $a_{1 h}=0.04 \mathrm{~m} / \mathrm{s}^{2}$ and did not impair the comfort of use of the footbridge (acceptable value $a_{h, \max }=0.1-0.2 \mathrm{~m} / \mathrm{s}^{2}$ ).

The second mode shape can be easily excited by slowly running persons and by jumping persons (intentional excitation and act of vandalism). The amplitudes of the vibration acceleration reached the values of $a_{1 v}=0.33 \mathrm{~m} / \mathrm{s}^{2}$ (during excitation by one running person), $a_{2 v}=0.42 \mathrm{~m} / \mathrm{s}^{2}$ (during excitation by one jumping person) and $a_{3 v}=0.81 \mathrm{~m} / \mathrm{s}^{2}$ (during excitation by three jumping persons).

According to the guidelines presented in Ref. [3], the footbridge can be classified into Class IV (seldom used footbridge, built to link sparsely populated areas or to ensure continuity of the pedestrian footpath in

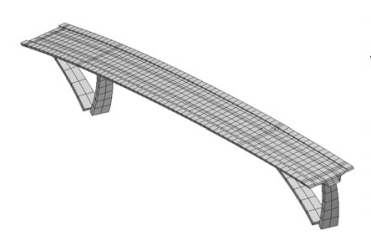

(a)
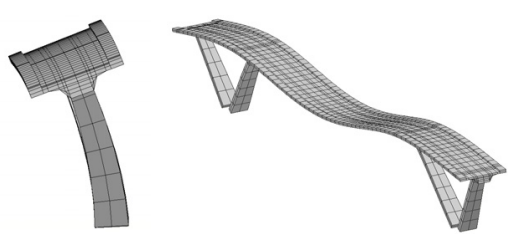

(b)

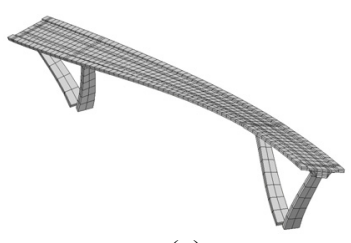

(c)

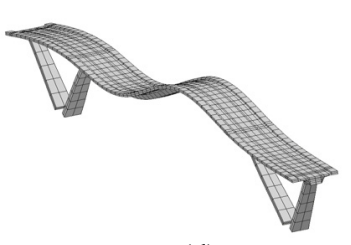

(d)

Fig. 3 The first four mode shapes of the footbridge obtained during numerical modal analysis: (a) horizontal (transversal) $f_{1}$ $=1.16 \mathrm{~Hz}$; (b) vertical $f_{2}=2.33 \mathrm{~Hz}$; (c) horizontal (transversal) $f_{3}=2.57 \mathrm{~Hz}$; (d) vertical $f_{4}=5.13 \mathrm{~Hz}$. 
motorway or express lane areas). Class IV footbridges are considered not to require any calculation to check dynamic behaviour. For very light footbridges, it seems advisable to select at least Class III (footbridge for standard use, which may occasionally be crossed by large groups of people but that will never be loaded throughout its usable area) to ensure a minimum amount of vibration control.

According to the criteria presented in Refs. [2, 3, 7], the footbridge can be placed in the group of structures rarely excited by pedestrians. In this case, the acceptable levels of vibration acceleration are in the range of $a_{v r \text {, max }}=0.85-1.2 \mathrm{~m} / \mathrm{s}^{2}$ for vertical vibrations and $a_{h r, \max }=0.2-0.3 \mathrm{~m} / \mathrm{s}^{2}$ for horizontal vibrations. The requirements of the comfort criteria are fulfilled in case of all rare occurring conditions of use such as running or jumping. Under the normal conditions of use, the comfort requirements are met with a wide margin of safety (with very small risk of exceeding). The deck vibrations are not felt by walking persons but are felt by standing persons what was confirmed during the tests.

In further analysis, the structural stiffness, mass of the superstructure and logarithmic decrement were calculated (Table 1).

2.2 Footbridge over Powstanców Ślaskich Av. in Kraków, Poland

The footbridge was built in 2005. This is a two-span girder footbridge with two girders of variable height, vertically curved deck (the radius of curvature $R=980.0 \mathrm{~m}$ ) and spans of $40.0+40.0 \mathrm{~m}$. The height of the girders varies from $1.3 \mathrm{~m}$ to $2.1 \mathrm{~m}$. The usable width of the footbridge is $4.0 \mathrm{~m}$. The girders are made with prestressed concrete C30/37 $\left(E_{c m}=32.0 \mathrm{GPa}, \gamma_{m}=2,600 \mathrm{~kg} / \mathrm{m}^{3}\right)$ and are supported on three concrete piers by means of elastomeric bearings. On the central pier, the girders are additionally supported by means of two steel hot rolled beams HEA100 mounted on both sides of the elastomeric bearings beside the bearings concrete pads (bearings seats). The steel beams were mounted after the cracking of the concrete girders over the central pier during the footbridge operation to limit the rotation of the girders around the horizontal axis transverse to the axis of the footbridge. In Fig. 4, the longitudinal section and cross section of the footbridge are presented.

Table 1 Structural stiffness, logarithmic decrement and the mass of the superstructure of the footbridge.

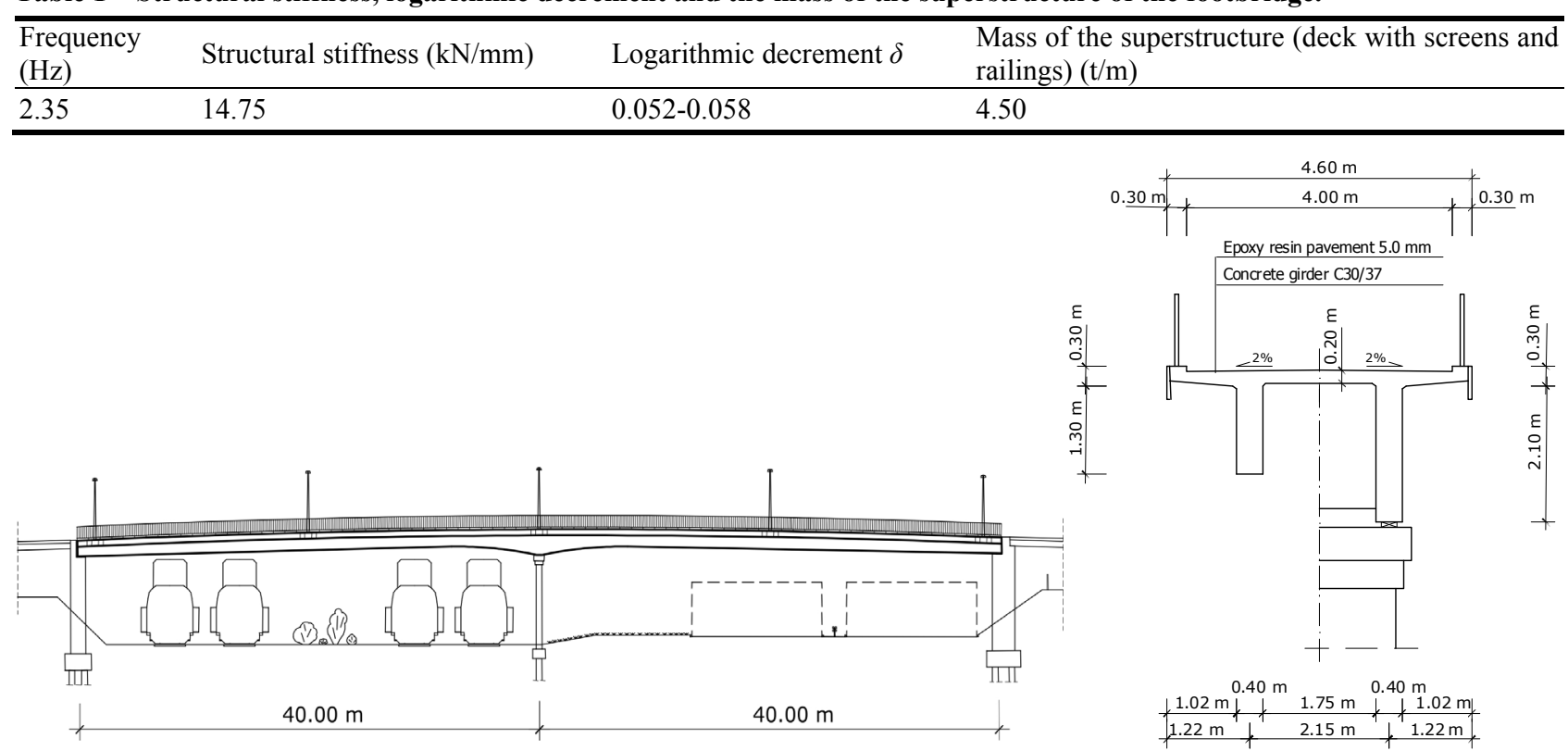

Fig. 4 Footbridge over Powstanców Śląskich Av. in Kraków, Poland. 
The computational FEA model of the footbridge was prepared in AASP. The 3D model was built using 2D plate elements available in the AASP. The supports of the girders on the central pier were modeled with constrained $X, Y$ and $Z$ translation (fixed bearing) and constrained $X, Y$ and $\mathrm{Z}$ rotation due to limited rotation of the girders supported on the central pier by means of bearings and additional steel beams ( $X$-longitudinal axis of the footbridge, $Y$-transverse axis, $Z$-vertical axis). The kinematic constraints were placed in nodes of FEA model in place and over a length corresponding to the accurate location of the support points in a real structure. The supports on the both ends of the footbridge were modeled with constrained $Y$ and $Z$ translation, elastic $X$ translation $\left(k_{x}=800.0 \mathrm{MN} / \mathrm{m}\right.$, assumed taking into account elasticity of elastomeric bearings and rubber expansion joints cover) and constrained $X$ rotation. The $Y$ and $Z$ rotations were modeled as unblocked (free).

During the numerical modal analysis, the modal shapes presented below were calculated (Fig. 5).

The dynamic field tests were performed with frequency $f_{t 1}=2.44 \mathrm{~Hz}$, identified during the tests, and often induced during everyday use of the footbridge as observed during the monitoring of the footbridge. The footbridge vibrations were induced by one to three walking, running and jumping persons. Three two-axis accelerometers were mounted on the edge of the footbridge deck in $1 / 2 L$ on both spans and in $1 / 3 L$ on the left span. To identify the mode shapes of the footbridge, the correlation of the measuring

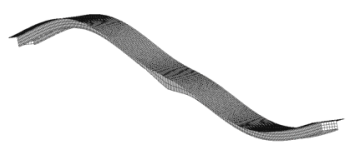

(a)

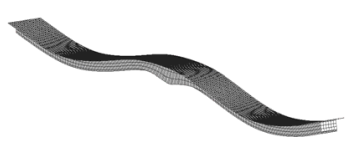

(b) signal was verified. The resonant vibration of the footbridge was induced using the metronome set at a rate corresponding to the natural vibration frequencies of the footbridge ( 146 beats/min.).

The recorded maximal vibration accelerations were: $a_{1 v}=0.15 \mathrm{~m} / \mathrm{s}^{2}$ (during excitation by one running person), $a_{2 v}=0.27 \mathrm{~m} / \mathrm{s}^{2}$ (during excitation by three running persons), $a_{3 v}=0.33 \mathrm{~m} / \mathrm{s}^{2}$ (during excitation by one jumping person), $a_{4 v}=0.43 \mathrm{~m} / \mathrm{s}^{2}$ (during excitation by three jumping persons). The footbridge can be classified into Class III and the acceptable level of vibration acceleration can be assumed as for rare occurring vertical vibration $a_{v r \text {, } \max }=0.85-1.2 \mathrm{~m} / \mathrm{s}^{2}$. However, the footbridge fulfils the requirements of the vibrational comfort criteria both for rare and everyday occurring vibrations. The comfort of use of the footbridge will not be impaired but the vibrations of the footbridge deck will be clearly felt by standing persons in case of their excitation by runners or vandals. The other characteristics of the footbridge are presented in Table 2.

\subsection{Footbridge over D5 Motorway near Cekov, Czech Republic}

The footbridge is a single span arch footbridge with reinforced concrete deck connected with reinforced concrete arch by means of steel square pipes $(200 \times$ $200 \times 20 \mathrm{~mm}$ ) filed with polyurethane foam. The arch is supported on concrete inclined foundation plates by means of steel bearings. The span of the arch is $69.00 \mathrm{~m}$ and the rise of the arch is $3.34 \mathrm{~m}$. Usable width of the deck is $3.00 \mathrm{~m}$ and its longitudinal slope

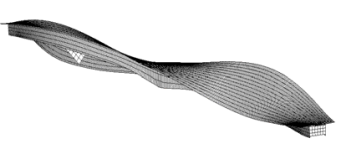

(c)

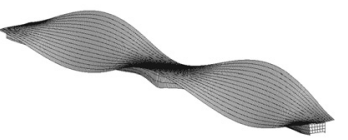

(d)

Fig. 5 The first four mode shapes of the footbridge obtained during numerical modal analysis: (a) vertical $f_{1}=2.45 \mathrm{~Hz}$; (b) vertical $f_{2}=2.69 \mathrm{~Hz}$; (c) torsional $f_{3}=3.88 \mathrm{~Hz}$; (d) torsional $f_{4}=4.47 \mathrm{~Hz}$.

Table 2 Structural stiffness, logarithmic decrement and the mass of the superstructure of the footbridge.

\begin{tabular}{llll}
\hline $\begin{array}{l}\text { Frequency } \\
(\mathrm{Hz})\end{array}$ & Structural stiffness $(\mathrm{kN} / \mathrm{mm})$ & Logarithmic decrement $\delta$ & $\begin{array}{l}\text { Mass of the superstructure (girders with deck and } \\
\text { railings })(\mathrm{t} / \mathrm{m})\end{array}$ \\
\hline 2.44 & 10.45 & $0.048-0.054$ & 5.90 \\
\hline
\end{tabular}


$5.5 \%$. The length of steel pipes connecting the arch and the deck varies from $5.40 \mathrm{~m}$ to $0.275 \mathrm{~m}$. The footbridge was built in 1995 .

The dynamic field tests of the footbridge were carried out in August, 2010. In numerical dynamic analysis of natural frequency and mode shapes of the footbridge, the time dependent material constants, after 15 years of footbridge operation $(t=5,400 \mathrm{~d})$, were used according to Ref. [8]. The deck was modeled as a concrete plate with variable thickness 0.35-0.50 m made of concrete C35/45 (Fig. 6), $\left(E_{c m}(t)\right.$ $=38.0 \mathrm{MPa}, \gamma_{m}=2,600 \mathrm{~kg} / \mathrm{m}^{3}$ - equivalent density of the deck with asphalt pavement and railings). The arch was modeled as a concrete plate with thickness $0.80 \mathrm{~m}$ made of concrete $\mathrm{C} 45 / 55,\left(E_{c m}(t)=40.0 \mathrm{MPa}, \gamma_{m}=\right.$ $2,500 \mathrm{~kg} / \mathrm{m}^{3}$ ). In Fig. 4, the longitudinal section and cross section of the footbridge are presented.

The computational FEA model of the footbridge was prepared in AASP. The 3D model was built using 2D plate elements and 2D beam elements available in the AASP. The supports of the arch were modeled with constrained $X, Y$ and $Z$ translations, constrained $X$, $Z$ rotations and elastic $Y$ rotation $\left(k_{R y}=40.0\right.$ $\mathrm{MNm} / \mathrm{deg}$ ). The supports of the deck on both ends were modeled with elastic $X$ translation $\left(k_{x}=600.0\right.$ $\mathrm{MN} / \mathrm{m}$ ) constrained $Y$ and $Z$ translations, constrained $X, Y$ rotation and unconstrained (free) $Z$ rotation.

Fundamental mode shapes of the footbridge are presented in Fig. 7. During the field tests, the first three mode shapes were identified with frequencies: $f_{t 1}$ $=1.37 \mathrm{~Hz}, f_{t 2}=2.12 \mathrm{~Hz}$ and $f_{t 3}=2.49 \mathrm{~Hz}$.

The vibration excitations during the field tests were performed for frequency $f_{t 3}=2.49 \mathrm{~Hz}$. The footbridge vibrations were induced by one to three walking, running and jumping persons. The two-axis accelerometers were mounted on the edge of the footbridge deck in $1 / 2 L$ and in $1 / 3 L$. To identify the mode shapes of the footbridge, the correlation of the measuring signal was verified. The resonant vibration of the footbridge was induced using the metronome set at a rate corresponding to the natural vibration frequencies of the footbridge ( 150 beats $/ \mathrm{min}$.).

The maximal amplitudes of the vibration acceleration recorded during the tests reached the values of $a_{1 v}=0.20 \mathrm{~m} / \mathrm{s}^{2}$ (during excitation by one running person), $a_{2 v}=0.48 \mathrm{~m} / \mathrm{s}^{2}$ (during excitation by three running persons), $a_{3 v}=0.52 \mathrm{~m} / \mathrm{s}^{2}$ (during excitation by three jumping persons). The requirements

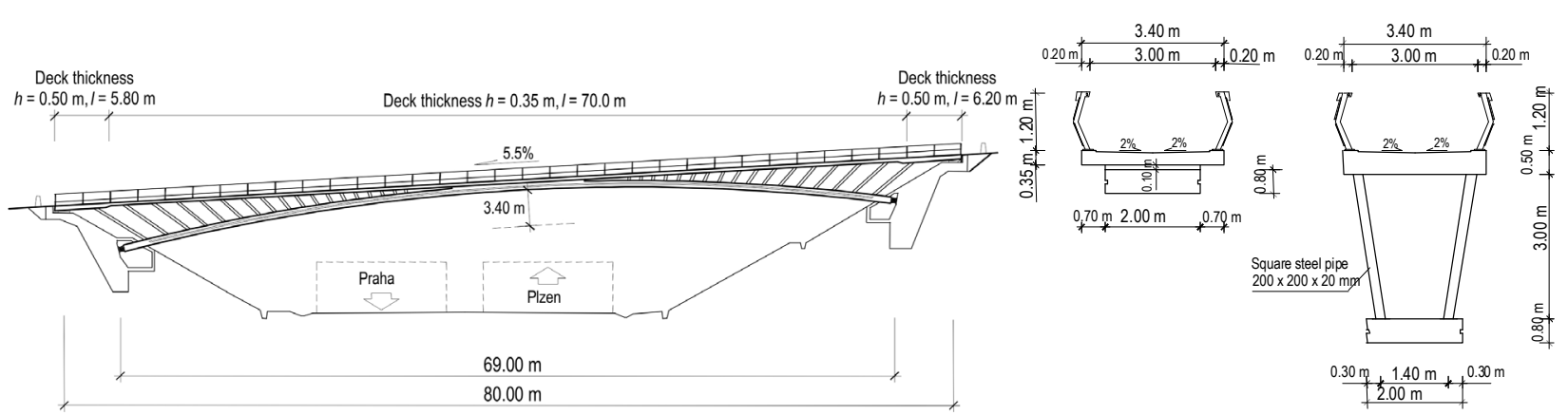

Fig. 6 Footbridge over D5 motorway near Cekov, Czech Republic.

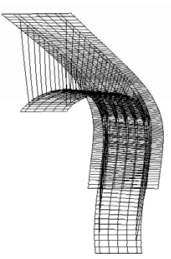

(a)

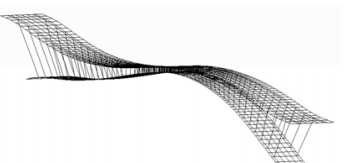

(b)

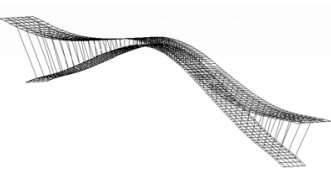

(c)

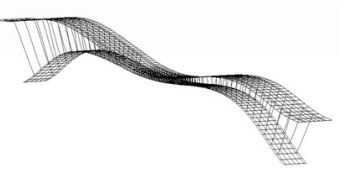

(d)

Fig. 7 The first four mode shapes of the footbridge obtained during numerical modal analysis: (a) horizontal (transversal) $f_{1}=1.46 \mathrm{~Hz}$; (b) vertical $f_{2}=2.15 \mathrm{~Hz}$; (c) vertical $f_{3}=2.36 \mathrm{~Hz}$; (d) vertical $f_{4}=3.55 \mathrm{~Hz}$. 
Table 3 Structural stiffness, logarithmic decrement and the mass of the superstructure of the footbridge.

\begin{tabular}{llll}
\hline $\begin{array}{l}\text { Frequency } \\
(\mathrm{Hz})\end{array}$ & Structural stiffness $(\mathrm{kN} / \mathrm{mm})$ & Logarithmic decrement $\delta$ & Mass of the superstructure (arch with deck and railings) (t/m) \\
\hline 2.49 & 24.10 & $0.098-0.110$ & 5.45 \\
\hline
\end{tabular}

of the comfort criteria on the footbridge are fulfilled with a wide margin of safety also in case of intentional vibration excitation. The footbridge is located near Cekov village in the agricultural region and, according to Ref. [3], can be classified into Class IV. The footbridges classified in Class IV do not require dynamic analysis and verification of the comfort of use criteria. However, this is an example of very stiff and good designed footbridge which ensures the comfort of use even during an intensive use defined in Ref. [3] for footbridges in Class I (urban footbridges linking up high pedestrian density areas, frequently used by dense crowds, subjected to very heavy traffic).

In Table 3, the structural stiffness, mass of the superstructure and logarithmic decrement of the footbridge are presented.

\section{Discussion and Results}

The results of dynamic field tests show that natural frequencies of all tested concrete footbridges are in a range of frequency of the users' vertical dynamic impact during fast walking, running and jumping $(2.20-3.00 \mathrm{~Hz})$ [10]. In this cases, it is possible to induce the resonant vibration of the structure during its normal use, especially by slow running persons (2.20-2.70 Hz-frequency range of vertical dynamic action during slow running). In case of the first rigid frame footbridge over A4 motorway, it is also possible to induce the resonant vibration of the first horizontal mode shapes by walking users (0.80-1.20 $\mathrm{Hz}$ - frequency range of horizontal dynamic action during walking).

The vibration accelerations recorded during the dynamic tests on examined footbridges were in the range of $a_{v}=0.15-0.80 \mathrm{~m} / \mathrm{s}^{2}, a_{h}=0.02-0.04 \mathrm{~m} / \mathrm{s}^{2}$ and did not exceed the limit values for vertical vibrations $a_{v, \max }=0.5-1.0 \mathrm{~m} / \mathrm{s}^{2}$ and for horizontal vibrations $a_{h, \max }=0.1-0.2 \mathrm{~m} / \mathrm{s}^{2}$. Further analyses show that obtained results depend mainly on the high stiffness and mass of the investigated footbridges. The logarithmic decrement of damping $\delta$ for tested footbridges is in the range of low damping $(\delta<0.10)$. As set forth in Ref. [11] on the basis of the dynamic field tests of 35 footbridges, $50 \%$ of tested footbridges have $\delta=0.05 \sim 0.10,30 \%$ of which have $\delta=0.03 \sim$ 0.05 ). Only $11 \%$ footbridges had $\delta=0.10 \sim 0.15$. Characteristic for the footbridges is also lack of the structures with a large damping $(\delta>0.20)$.

In case of steel footbridges, the logarithmic decrement of damping $\delta$ is very often in the range of $0.01-0.02[7,12]$. The stiffness of the medium span steel footbridges is in the range of $1.5-3.0 \mathrm{kN} / \mathrm{mm}$ and their mass per unit length is $0.10-0.50 \mathrm{t} / \mathrm{m}$. It leads to general conclusion that investigated concrete footbridges mostly due to their large stiffness $(10.0-25.0 \mathrm{kN} / \mathrm{mm})$ and large mass $(4.0-6.0 \mathrm{t} / \mathrm{m})$ are much more resistant to dynamic impact of the pedestrians than lightweight and flexible steel footbridges. The further researches concerning the determination of influence of structural mass and stiffness on the dynamic response of the footbridges are recommended.

During the numerical calculation of natural frequencies of the footbridges, the high impact of the supports elasticity/stiffness and elasticity/stiffness of expansion joint cover into obtained results was observed. In the computational FEA models, the elastic (spring) supports matched by successive attempts were used to ensure the compatibility of the calculated and measured mode shapes of the footbridges. It is recommended to elaborate a recommendation and more accurate method of estimation of the stiffnesses of different types of bridge bearings and stiffnesses of the expansion join cover for their use in dynamic analyzes. 


\section{Conclusions}

In all presented examples of the medium span concrete footbridges, the requirements of vibrational comfort criteria were fulfilled with a wide margin of safety for the most probable cases of dynamic loads during footbridge exploitation. The logarithmic decrement of the tested concrete footbridges, although it is relatively higher than in steel footbridges, is still in the range of low damping as in the steel and composite footbridges. However, in comparison with steel and composite footbridges, analysed concrete footbridges are characterised by higher structural stiffness and higher mass of superstructure. These features of the concrete structures ensure the fulfilment of the comfort criteria requirements also for higher spans length than in case of lightweight steel or composite structures.

\section{References}

[1] A. Flaga, M. Pańtak, Vibration comfort criteria for pedestrians on footbridges, in: Proceedings of the Third International Conference "Footbridge 2008: Footbridge for Urban Renewal”, Porto, 2008, pp. 263-268.

[2] M. Pańtak, A. Flaga, Experimental verification of own vibration comfort criteria for footbridges, in: Proceedings of the Seminar Wroclaw Bridge Days "Footbridges, Architecture, Design, Construction, Research", Educational Publishing House of Lower Silesia, Wrocław, 2007, pp. 233-246. (in Polish)

[3] Footbridges - Assessment of Vibrational Behaviour of Footbridges Under Pedestrian Loading, Service d'études techniques des routes et autoroutes-Sétra (Road and
Highway Technical Studies Department), Sétra, French, 2006.

[4] H. Bachmann, W. Ammann, F. Deischl, J. Eeisenmann, I. Floegl, G.H. Hirsch, et al., Vibration Problems in Structures-Practical Guidelines, Birkhäuser Verlag, Germany, 1995.

[5] H. Bachmann, W. Ammann, Vibrations in Structures Induced by Man and Machines, IABSE (International Association for Bridge and Structural Engineering), Zurich, 1987.

[6] EN 1990:2002/A1:2005, Eurocode: Basis of Structural Design: Annex A2, CEN (European Committee for Standardization), 2004.

[7] M. Pańtak, B. Jarek, W. Średniawa, Application of EN 1990/A1 vibration serviceability limit state requirements for steel footbridges, Procedia Engineering 40 (2012) 345-350.

[8] EN 1992-1-1:2004, Eurocode 2: Design of Concrete Structures. Part 1-1: General Rules and Rules for Buildings, CEN (European Committee for Standardization), 2004.

[9] R. Menšík, V. Kanický, V. Salajka, Footbridge over D5 near Cekov, DOSING (Dopravoprojekt Brno Group Ltd.) [Online], http://www.dosing.cz (accessed Dec. 4, 2013).

[10] H. Bachmann, "Lively" footbridges - A real challenge, in: Proceedings of the International Conference "Footbridge 2002", Paris, 2002, pp. 18-30.

[11] M. Salamak, The role of damping in footbridges and methods of its identification, in: Proceedings of the Seminars "Design, Construction and Aesthetics of Footbridges", Cracow, 2003, pp. 189-213. (in Polish)

[12] M. Pańtak, Dynamic characteristics of medium span truss, cable-stayed and suspension steel footbridges under human-induced excitation, in: Proceedings of the International Conference "Footbridge 2011 Attractive Structures at Reasonable Costs", Wrocław, 2011, pp. 1209-1214. 